\title{
The Impact of Competitive Strategies, and Strategic Human Resource Management on Firm Performance of Palestine
}

\author{
Nermeen Sayyad \\ Al-Quds University, Faculty of Business and Economics \\ Department of Business Administration Jerusalem, Palestine
}

\begin{abstract}
This paper examines the impact of competitive strategies and strategic Human Resource Management on Firm Performance of Palestine from various critical perspectives. Rapid environmental changes, competition to provide innovative products and services, changing customer and investor demands and globalization have become the standard backdrop for firms. Sustained competitive advantage could be generated from a firm's human capital by designing strategic human resource management to diagnose a firm's strategic needs which is required to implement a competitive strategy and achieve operational goals. Effective human resource management strategy systematically organizes all individual human resource management measures to directly influence employee attitude and behavior in a way that leads business to achieve its competitive strategy. The researcher has selected corporate and non-corporate firms as well as small and Medium Corporation were chosen in different areas of Palestine (south, north, and middle) 106 respondents selected from 45 firms across the three zones of Palestine. The general objective of the study is to investigate the place of Strategic Human Resource Management in improving corporate performance among mentioned firms in Palestine. The study used descriptive statistics (frequencies, means and percentages) to answer the three research questions posed for the study. The Spearman Rank Correlation Coefficient was used to test the three hypotheses that guided the study. The final results showed that there is a strong positive correlation between strategic HRM and performance level of competition in the firms. It was also concluded that SHRM is an important and indispensable tool for any organizations performance and for any organization that wants to gain competitive advantage over others. Finally, this article develops a conceptual framework that explains the relationship between strategic human resource management, competitive strategies and firm Performance.
\end{abstract}

Key Words: Strategic human resource management, Firm performance, Competitive strategy, Palestine

\section{INTRODUCTION}

The word organization implies that there is a holistic system, members of this system are in some way committed or obligated to it, and that the system is arranged according to some kind of designated design or structure (April Young love 2006). The organizations usually have resources at their disposal which they deploy to realizing their goals and objectives. These resources are: Capital, Land, Labor (Human) and Technology. Humans are an organization's greatest assets; humans and the potential they possess drive an organization (Christine Jahn 2007). Today's organizations are continuously changing. Organizational change impacts not 
only the business but also its employees. In order to maximize organizational effectiveness, human potential—individuals' capabilities, time, and talents—must be managed.

Organizations are seeking to create much competition between them, taking more market, more customers, more sales, etc. Rapid changes stemming from globalization, advancement of information systems and other factors have caused higher competition. Many organizations are driven by the market to set their goals in their performance. Some of the goals are: cost reduction, achieving sales levels, increasing the number of customers, increasing the market percentage, improving productivity and quality, innovative products. The realization of these goals will be achieved through the human resources management in organizations. Workforce, as the key to success, will enable the achievement of organizational performance.

Human resources are regarded as one of the most important sources of today's firms. Human resources management is more important than other competitive sources because these people use other assets in organization, create competitiveness and realize objectives. Thus firstly, organizations must understand the expectations of their workforce in order to achieve the desired performance. The realization of expectations of employees will enable the desired behavior of employees in the organization. The desired outcomes of the organization in managing their workforce are: competence, cooperation of employees with managers, cooperation of employees between them, showing the capabilities of employees; motivation, commitment and satisfaction; attitude and presence; employee behaviors.

The overall goal of performance management is to create a culture as high performance in which individuals and teams to take responsibility for the continuous improvement of business processes and their skills and contribute in achieving the targets set by managers. In particular, management performance can be expressed as the approximation of individual objectives of employees with organizational objectives provided that employees support the culture of the organization. (Armstrong, 2006).

The purpose of strategic human resource management is to improve business performance through people management. The organizations need to manage their human resources effectively and efficiently to achieve the desired goals and objectives. The achievement the goals and objectives translate also in better performance. So, the issues raised for discussion are: How should organizations manage their main source - human resources? Does strategic human resource management help to meet the needs, the goals and objectives of the business? As should be adapted strategic human resource management to realize the performance? How should adapt strategic management of human resources to increase organizational performance? The main objectives of the study are:

1. To observe closely how applicable is in practice the theoretical aspect of strategic human resource management for the achievement the organizational performance in Palestine.

2. To observe if organizations use the strategy of human resource management for the achievement of their performance objectives.

3. To observe the importance of these strategies in the organization and in their performance in Palestine.

4. Is there any relationship between Strategic Human Resource Management and organizational success in Palestinian firms?

5. Do Palestinian firms practice SHRM differently?

6. Does Strategic HRM have any significant effect on organizational performance?

7. Does SHRM give some organizations an edge over others that do not practice it 


\section{Human Resources Defined}

\section{LITERATURE REVIEW}

Human Resources (HR) has been given many definitions over the years, but the two most popular definitions given by the American Heritage Dictionary are "the persons employed in a business or organization" (Houghton Mifflin Company [HMC], 2000) and "the field of personnel recruitment and management"(HMC). Both definitions fail to provide the key insight into the power of HR policies, strategies and quality personnel to be able to create substantial competitive advantage for an organization. The HR field has changed dramatically from the original HR departments of the early and mid-twentieth century to today. These original HR departments (called personnel departments at the time) existed primarily to hire new employees and administer employee benefits.

The achievements of organizational objectives can be different in different organizations. The studies emphasize the impact of HRM on organizational performance. Basically, and other studies in this area, point out that it is necessary to achieve organizational objectives and management of human resources should be strategic. Also, the strategies of human resource management should be integrated with the overall organizational strategy in the context of achieving performance. There has been much research on strategic human resource management that affects organizational performance. The discussions and definitions will be divided in two parts of speech: the strategic management of human resources and organizational performance.

\section{Strategic Hrm Concept}

Strategic HRM is a process that involves the use of overarching approaches to the development of HR strategies, which are integrated vertically with the business strategy and horizontally with one another. These strategies define intentions and plans related to the overall organizational considerations, such as organizational effectiveness, and to more specific aspects of people management, such as; resourcing, learning and development, reward and employee relations. Strategic HRM focuses on actions that differentiate the firm from its competitors (Purcell, 1999). It is suggested by Hendry and Pettigrew (1986) that it has seven meanings:

$>$ The use of planning;

$>$ A coherent approach to the design and management of personnel;

> Systems based on an employment policy and workforce strategy;

$>$ Often underpinned by a "philosophy";

$>$ Matching HRM activities and policies to some explicit business strategy;

$>$ Seeing the people of the organization as a strategic resource;

$>$ Achievement of competitive advantage (Armstrong, 2006).

Strategic HRM has a clear focus on implementing strategic change and growing the skill base of the organization to ensure that the organization can compete effectively in the future (Holbeche, 2004). SHRM facilitates the development of a human capital that meets the requirements of business competitive strategy, so that organizational goals and mission will be achieved (Guest, 1987). Strategy of human resource management is an integral part of business strategy. The main focus of this strategy is to achieve organizational objectives. So, strategy, then, is a set of strategic choices, some of which may be formally planned. It is inevitable that much, if not most, of a firm's strategy emerges in a stream of action over time (Boxall and Purcell, 2003). 


\section{Organizational Performance Concept}

Campbell's (1999) theory defines performance as behavior or action relevant to the attainment of an organization's goals that can be scaled, that is, measured. Moreover, job performance is defined as what one is paid to do, or what one should be paid to do. The theory states that the measurement options, be they ratings from a supervisor, peer, or self, a simulated work sample, or hard criteria (e.g. tallying revenue generated, costs saved, customer complaints, or some variant of a computerized performance assessment) besides being valid, reliable, and not deficient should be free of contamination from sources of variation that are not under the control of the individual (e.g. differences in technology impacting a person's performance). Situational enhancers or constraints, if not taken into account in an appraisal, can contaminate the mean, variance, or both with regard to an individual's performance. Observation and interpretation hold the key to the establishment of effective criteria. Yet, an ongoing problem in appraising people is the lack of reliability in the observation of their behavior (Ronan and Prien 1971). This unreliability is largely attributed to well-known rating errors such as "first impressions", "halo", and "similar-to-me". Lifson (1953) found that up to one-third of performance measurement variance is due to rater differences despite the fact that the observers had considerable experience in observing and evaluating people in the workplace. Lance (1994) corroborated this finding. Experience, however, is not a substitute for training. To solve the problem regarding lack of reliability, an observer must be trained. In this section, training programs that have been shown to be effective are described, and the necessity of taking context into account is explained (Boxall, Purcell and Wright, 2007).

Organizational performance is one of the most broadly and extensively used dependent variables in organizational studies today, and yet, at the same time, it remains one of the most imprecise and loosely-defined constructs (Rogers and Wright, 1998). In the strategy literature, the focus of attention on this construct has been concerned almost entirely with financial measures of performance. Conceptually, organizational performance has been defined as the comparison of the value produced by a company with the value owners expected to receive from the company (Alchian and Demsetz 1972). Ramanujam (1986) indicate that a narrow definition of performance focus on the use of simple outcome-based financial indicators that are assumed to reflect the fulfillment of the economic goals of the firm.

The literature reveals that studies into the HRM performance have not determined a specific and precise meaning for the organizational performance construct. Some studies have used subjective measures to evaluate firms' performance, such as employee satisfaction, customer satisfaction, executives' perceptions about the company's performance, absenteeism, employee commitment, and other behavior aspects. Other studies reference various objective measures for evaluating firms' performance, such as financial and market indicators. As a result, there is no common theory concerning organizational performance, and researchers utilize different indicators or variables to measure this construct. For this reason, there is also a call for a precise theory of organizational performance (Janssens and Steyaert, 2009) and HRM researchers and professionals might give crucial and special consideration to filling such a gap (Guest, 2011).

Another way, the concept of performance has been expressed by Brumbrach (1988) as follows: performance means both behaviors and results. Behaviors emanate from the performer and transform performance from abstraction to action. Not just the instruments for results, behaviors are also outcomes in their own right - the product of mental and physical effort applied to tasks - and can be judged apart from results. This definition of performance leads to the conclusion that when managing performance both inputs (behavior) and outputs (results) 
need to be considered. It is not a question of simply considering the achievement of targets, as used to happen in 'management by objectives' schemes. Competency factors need to be included in the process (Armstrong, 2006).

\section{Strategy and Human Resources Management}

In their seminal thesis on the development of HR function, Jamrog \& Overholt (2004:1) declared that "over the past 100 years the HRM professional has been continuously evolving and changing, adding more and different responsibilities". The authors' account shows that the HRM function has evolved through many stages, from the medieval time through the industrial revolution, the scientific management, the human relations movement, etc., to the present strategic business partner model. For most of its history, HR has mainly focused on the administrative aspects of HRM, except recently, with the strident call for HRM to become a strategic business partner (Ulrich, 1997; Brockbank 1999; Lawler III \& Mohrman, 2000; and Lawler III \& Mohrman, 2003). Some scholars therefore, are wont to differentiate between the traditional HRM and SHRM. Traditional HRM is transactional in nature, concerned essentially with providing administrative support in terms of staffing, recruitment, compensation and benefits (Rowden, 1999; and Wei, 2006). Ulrich (1997) argues that the HR function has been an administrative function headed by personnel whose roles are essentially focused on cost control and administrative activities. Managing people is therefore the responsibility of HR manager.

HRM is then a "formal system for the management of people within the organization" (Bateman \& Zeithaml, 1993:346). For Inyang (2001:8), HRM is simply "organization's activities, which are directed at attracting, developing and maintaining an effective workforce".

The many transactional or administrative activities involved in managing the human resources of an organization - training and development, staff motivation, compensation, staff commitment, quality performance, etc. are meant to be carried out effectively to influence the achievement of corporate objectives (Inynag, 2008a). The paradigm shift from the administrative aspects of HRM led to the emergence of SHRM as a new generation of valueadded core responsibility or function of HRM. The emphasis of SHRM is that of a strategic business partner. It now supports the company's competitive advantage by providing high quality people and by helping business managers strategically plans the functions of the human capital within the organizations (Rowden, 1999). SHRM, strongly beliefs that critical organizational capabilities or performance behaviors are sine qua non, for the attainment of a particular business strategy or goal.

Unlike the traditional HRM which covers a wide range of employment practices, including recruitment, selection, performance appraisal, training and development and administration of compensation and benefits, SHRM reflects a more flexible arrangement and utilization of human resources to achieve organizational goals, and accordingly helps organizations gain competitive advantage (Wei, 2006).

\section{Strategic Human Resources Management}

Strategic human resource management is a complex process which is constantly evolving and being studied and discussed by academics and commentators. Its definition and relationships with other aspects of business planning and strategy is not absolute and opinion varies between writers. The definitions below are from the CIPD book Strategic HRM: the key to improved business performance (Armstrong, $M$ et al 2002) within which there is comprehensive coverage of the various definitions and approaches to HRM, strategy and strategic HRM. Strategic HRM can be regarded as a general approach to the strategic 
management of human resources in accordance with the intentions of the organization on the future direction it wants to take. It is concerned with longer-term people issues and macroconcerns about structure, quality, culture, values, commitment and matching resources to future need. It has been defined as: All those activities affecting the behaviour of individuals in their efforts to formulate and implement the strategic needs of business (Schuler, R.S. 1992). The pattern of planned human resource deployments and activities intended to enable the forms to achieve its goals Wright, P.M. et al 1992).

Strategic HRM can encompass a number of HR strategies. There may be strategies to deliver fair and equitable reward, to improve performance or to streamline structure.

However, in themselves these strategies are not strategic HRM. Strategic HRM is the overall framework which determines the shape and delivery of the individual strategies.

Boxall and Purcell (2003) argue that strategic HRM is concerned with explaining how HRM influences organizational performance. They also point out that strategy is not the same as strategic plans. Strategic planning is the formal process that takes place, usually in larger organizations, defining how things will be done. However strategy exists in all organizations even though it may not be written down and articulated. It defines the organization's behavior and how it tries to cope with its environment. Strategic HRM is based on HRM principles incorporating the concept of strategy. So if HRM is a coherent approach to the management of people, strategic HRM now implies that that is done in a planned way that integrates organizational goals with policies and action sequences.

\section{Strategic Hrm and Business Strategy}

A good business strategy, one which is likely to succeed, is informed by people factors. One of the driving factors behind the evaluation and reporting of human capital data is the need for better information to feed into the business strategy formulation process. In the majority of organizations people are now the biggest asset. The knowledge, skills and abilities have to be deployed and used to the maximum effect if the organization is to create value. The intangible value of an organization which lies in the people it employs is gaining recognition by accountants and investors, and it is generally now accepted that this has implications for long term sustained performance. It is therefore too simplistic to say that strategic human resource management stems from the business strategy. The two must be mutually informative. The way in which people are managed, motivated and deployed, and the availability of skills and knowledge will all shape the business strategy?

It is now more common to find business strategies which are inextricably linked with and incorporated into strategic HRM, defining the management of all resources within the organization. Individual HR strategies may then be shaped by the business strategy. So if the business strategy is about improving customer service this may be translated into training plans or performance improvement plans.

\section{Strategic Hrm and Human Capital Management}

A number of writers have argued that strategic HRM and human capital management (HCM) are one and the same thing, and indeed the concept of strategic HRM matches that of the broader definition of HCM quite well as the following definition of the main features of strategic HRM by Dyer and Holder (1998) shows: - Organizational level - because strategies involve decisions about key goals, major policies and the allocation of resources they tend to be formulated at the top. Focus - strategies are business-driven and focus on organizational 
effectiveness; thus in this perspective people are viewed primarily as resources to be managed toward the achievement of strategic business goals. Framework - strategies by their very nature provide unifying frameworks which are at once broad, contingency-based and integrative. They incorporate a full complement of HR goals and activities designed specifically to fit extant environments and to be mutually reinforcing or synergistic.

This argument has been based on the fact that both HRM in its proper sense and HCM rest on the assumption that people are treated as assets rather than costs and both focus on the importance of adopting an integrated and strategic approach to managing people which is the concern of all the stakeholders in an organization not just the people management function. However, the concept of human capital management complements and strengthens the concept of strategic HRM rather than replaces it (Armstrong, $M$ et al 2002). It does this by: drawing attention to the significance of 'management through measurement', the aim being to establish a clear line of sight between HR interventions and organizational success providing guidance on what to measure, how to measure and how to report on the outcomes of measurement - underlining the importance of using the measurements to prove that superior people management is delivering superior results and to indicate the direction in which HR strategy needs to go.

\section{Shrm and Organizational Performance}

Although most studies speak of SHRM practices leading to performance, such a one-way line of causation is unsatisfactory (Edwards and Wright, 2001). The usual key criticism of SHRM practices and organizational performance is that sound theoretical development that explains how such SHRM practices operate is absent (Becker and Gerhart, 1996). In an effort to address such theoretical developments in the area, scholars have proposed to consider intermediate linkages between SHRM practices and organizational performance (Ferris et al, 1998). Thus the general consensus developed is that SHRM practices do not lead directly to organizational performance.

Rather they influence firm resources, such as the human capital, or employee behaviors, and it is these resources and behaviors that ultimately lead to performance; even though only a few researchers (Katou and Budhwar, 2006) have measured these mediators and addressed their 24 importance. Since the SHRM practices are not standardized and they only differ according to the aims and objectives of each individual research, Katou and Budhwar (2006) suggest use of "mediating model" which adopts two systems of SHRM practices that are usually present in almost all works, namely, resourcing/development, aiming at attracting and developing human resources; and rewards/relations, aiming at retaining and motivating human resources. Similarly,

Gerhart (2005) suggests application of motivation as a mechanism by which SHRM practices impact organization performance.

Motivation is affected by a variety of SHRM practices, including recruitment, training and development, work arrangements, compensation systems, and appraisal systems. However, considering that the literature highlights that most studies examining the relationship between SHRM practices and organization's performance have been conducted mostly in a few developed countries (US and UK), and that only a few researchers have measured the mediators and addressed their importance, the question still left unanswered is the influence of SHRM practices on human capital or specifically, motivation and, consequently organizational performance in other contexts (Katou and Budhwar, 2006). To fill this gap and to further examine the existence of such a relationship, it is important to conduct research in 
non-US/UK contexts. This study therefore seeks to investigate the association between SHRM practices and organization performance and also the mediating role of employee motivation in the Palestinian context.

Literature on SHRM shows that primarily there are three school of thoughts related to implementation of SHRM practices:

\section{Universalistic approach}

This is the simplest approach, which operates with a basic assumption that there is a linear relationship between variables and that can be extendable to entire population (Delery and Doty, 1996)

\section{Contingency approach}

Many researchers contend that contingency approach is more complex than universalistic approach because contingency approach is more inclined towards interactions rather than simple linear relationship (Schoonhoven, 1981; Van, A, and Drazin, 1985; Venkatraman, 1989).

\section{Configurational approach}

This is the most complex one because this approach is concerned about the synergetic effect of a certain SHRM practice (Doty, Glick, and Huber, 1994). Although there is more theoretical significance of contingency and configurationally approach, but both of these approaches lack statistical significance, while on the other hand, universalistic approach has more empirical significance (Syed et al., 2008). This study examines the implications of universalistic approach. We are using seven best practices of HRM that are described by Delery and Doty (1996) and further implemented by Syed et al., (2008), which are discussed below.

\section{Internal career opportunities}

Internal career opportunities refer to the tendency whether to hire employees mostly from within the organization or from the outside. According to Delery and Doty (1996), organizations give importance to internal hiring as compared to external. Pfeffe (1994) describes it as a give and take process in which managers promote their employees primarily from within the organization and show trust on them and in return expect greater performance.

The relationship between internal career opportunities and organizational performance is empirically supported by Blackwell, Brickley, and Weisbach (1994) and Shay (2006), who found a positive correlation between these variables. While, on the other hand, Gaertner and Nollen (1989) relate the promotion rate with psychological commitment.

Furthermore, Ngo and Tsang, (1998) provide support to Gaertner and Nollen's argument in their study of 778 business executives in Hong Kong,who found a positive impact on commitment.

\section{Training}

Training refers to the quantity of official training given to employees. Organizations may choose either to provide extensive official training or to rely on attaining expertise through selection. Literature on universalistic approach shows that training has the most significant effect on organization's performance (Pfeffer, 1998, Pfeffer and Veiga 1999, Harel and Tzafrirs, 1999, Syed et al., 2008, Shay, 2006). Several researchers are of the view that training is a 
universal best practice (Arthur, 1992, Delaney and Huselid, 1996, Huselid and Becker, 1996, Youndt, Snell, Dean, and Lepak, 1996).

In a study of Chinese firms, Syed et al. (2008) found training as the most influencing SHRM practice that accounted for $12.17 \%$ variance in organizational performance. Hatch and Dyer, (2004) found that extensive training caused fewer defects in products in their study of 25 semiconductor manufacturing firms. Huang (2001a, b) studied 568 Taiwan's companies and found a significant direct relationship among training and product and service quality. The findings of the study of managerial attitude toward HRM by Jennings, Cyr, and Moore, (1995) also found training and development to be the most significant SHRM practice, thereby supported the earlier studies.

\section{Employee participation}

Several researchers believe that employees' participation is directly associated with organization's performance (Arthur, 1992, Batt; Pfeffe, 1994; Colvin, and Keefe, 2002; Hodson, 2002; Kato and Morishima, 2002; Shay, 2006). Batt, Colvin, and Keefe, (2002) found an indirect relationship between employee participation in decision making and employee turnover rate. While Hodson, (2002) found another dimension and showed that workplace conflicts could be reduced through employee participation.

\section{Result-oriented appraisals}

According to Delery and Doty (1996), primarily appraisals are based on two types: results based and behavior based. Behavior-based appraisals focus on the specific behaviors that best match the job while result-oriented appraisals focus purely on the results of those behaviors. In a result-oriented appraisal system, certain incentives are given to employees on completion of their performance objectives (Pfeffer, 1998). Delery and Doty, (1996) found a significant positive relationship between result-oriented appraisal and organizational performance. Furthermore, the study by Syed et al., (2008) also showed similar results.

\section{Profit sharing}

Profit sharing refers to the integration of pay with organizational performance. Delery and Doty, (1996) found a positive significant relationship of profit sharing with performance. In a study of Chinese firms Syed et al., (2008) investigated the impact of profit sharing on two fold performance measures and found a unique relation in which profit sharing had a positive significant relation with only financial measures of organizational performance and not significant relation with other dimensions of performance ( product/service quality).

\section{Employment security}

The importance of employment security is emphasized by Pfeffer, (1998) who holds that it is unrealistic on the part of the organizations to expect hard work, devotion and commitment from their employees in the absence of employment security. Syed et al., (2008) found a positive significant relationship between employment security and organizational performance. Furthermore, Pfeffer, (1998) describes that the importance of employment security according to firm's point of view is twofold: cost; and competition.

If organization does not provide its employees with job security then they obviously switch towards better opportunities and thus increasing cost (training, selection etc) and competition.

\section{Job description}

The degree to which job duties are well defined is very important. Delery and Doty, (1996) find a moderate correlation between job description and a firm's performance. 
Furthermore, the study by Syed et al., (2008) shows that $8.30 \%$ variance in organizational

Performance is observed due to job description.

\section{What is performance measurement?}

Performance measurement is simply a method for assessing progress towards stated goals. It is not intended to act as a reward/punishment mechanism, but rather as a communication and management tool. In Performance Measurement and Evaluation: Definitions and Relationships (GAO/GGD-98-26), the U.S. General Accounting Office (GAO) defines performance measurement as the ongoing monitoring and reporting of program accomplishments, particularly progress towards pre-established goals. It is typically conducted by program or agency management. Performance measures may address the type or level of program activities conducted (process), the direct products and services delivered by a program (outputs), and/or the results of those products and services (outcomes). A program" may be any activity, project, function, or policy that has an identifiable purpose or set of objectives.

Performance measures quantitatively tell us something important about our products, services, and the processes that produce them. They are a tool to help us understand, manage, and improve what our organizations do. Effective performance measures can let us know:

How well we are doing, · If we are meeting our goals, · If our customers are satisfied, · If our processes are in statistical control, and - If and where improvements are necessary.

They provide us with the information necessary to make intelligent decisions about what we do. A performance measure is composed of a number and a unit of measure. The number gives us a magnitude (how much) and the unit gives the number a meaning (what). Performance measures are always tied to a goal or an objective (the target). Performance measures can be represented by single-dimensional units like hours, meters, nanoseconds, dollars, number of reports, number of errors, number of CPR-certified employees, length of time to design hardware, etc. They can show the variation in a process or deviation from design specifications. Single-dimensional units of measure usually represent very basic and fundamental measures of some process or product. More often, multidimensional units of measure are used.

\section{Relationship between Organizational Effectiveness and Human Resources Management} Most of the early reviews of the literature were published by notable industrial psychologists as cited in Ferris (et al., 1999). As a consequence, these reviews tended to emphasize applied individual-level issues, such as employee testing, training and motivation.

Gilmer's (1960) discussion of situational variables explicated the importance of matching personnel strategies with organizational strategies. Further, Gilmer invited researchers to design measures to assess the relationship between "individual personalities" and "company personalities" (1960 as cited in Ferris et al., 1999).

Some researchers have proposed that evaluations of effectiveness should be based on financial measures (e.g., profit) and for years, human resources issues have been secondary to such measures. Today, many CEOs agree that profit alone is not enough to hold the enthusiasm and loyalties of employees or to call attention to the vital elements of a business that must receive attention if it is to perform effectively (Watson, 1991 as cited in Zellars \& Fiorito, 1999). Under the threat of exit (Hill \& Jones, 1992), organizations now recognize that they must fulfil 
responsibilities to many constituencies (Baumhart, 1968; Clarkson, 1991 as cited in Zellars \& Fiorito, 1999), including employees.

Mohrman \& Lawler III, (1997) advocates that an organization is created in which the human resource management practices of the past no longer fit. Organizations are faced with a situation that cries out for new solutions to the thorny challenges of integrating business and people needs.

Acquaah (2004) states that human resource management practices enhance organizational effectiveness and performance by attracting, identifying, and retaining employees with knowledge, skills, and abilities, and getting them to behave in a manner that will support the mission and objectives of the organization. Thus, the effectiveness of HRM practices depends on how it engenders the appropriate attitudes and behaviors in employees, in addition to its implementation.

Today, HR departments are expected to contribute to organizational performance (Ettore, et al. 1996; Fitz-enz, 1994; Mathes, 1993), and many organizations now believe that the success of the strategic management process largely depends on the extent to which the HR function is involved (Butler, et al. 1991 as cited in Zellars \& Fiorito, 1999).

Studies at the last decade (e.g., Arthur, 1994; Delery \& Dory, 1996; Huselid, 1995; Huselid \& Becker, 1996; Huselid, Jackson \& Schuler, 1997 as cited in Dyer \& Shafer, 1998) have reported rather large effects on such outcomes as employee turnover, productivity, quality, profits, and even stock prices. Trouble is, for a variety of methodological reasons - including unreliable measures of HRM and OE, common method variance, poorly specified models, and crosssectional rather than longitudinal research designs - these estimates strain credibility to the point of incredulity (Becker \& Gerhart, 1996 as cited in Dyer \& Shafer, 1998).

Over time, employees who feel neglected will seek alternatives and may withdraw either through increased absenteeism and turnover or decreased commitment. This may threaten the firm's survival or at least hinder its success as other sources of competitive advantage such as scale economies and protected markets wane - "what remain as a crucial, differentiating factor is the organization, its employees, and how they work" (Pfeffer, 1994, p.14 as cited in Zellars \& Fiorito, 1999).

It is important that a firm adopt HRM practices that make best use of its employees. This trend has led to increased interest in the impact of HRM on organizational performance, and a number of studies have found a positive relationship between so-called "high-performance work practices" (Huselid, 1995) and different measures of company performance. Furthermore, there is some empirical support for the hypothesis that firms, which align their HRM practices with their business strategy, will achieve superior outcomes (Bae \& Lawler, 1999). (CResearch Institute for Progression of Knowledge www.ripknet.org 


\section{SURVEY ANALYSIS}

Table 1: Socio-Demographic characteristics of the Respondents

\begin{tabular}{|l|l|l|}
\hline Age of Business & Frequency & percentage \\
\hline $0-5$ & 10 & 9 \\
\hline $6-10$ & 54 & 51 \\
\hline More than 10 & 42 & 40 \\
\hline Total & 106 & 100 \\
\hline Number of employees & & \\
\hline Below 50 & 47 & 44 \\
\hline & & \\
\hline $51-100$ & 36 & 34 \\
\hline Above 100 & 23 & 22 \\
\hline Total & 106 & 100 \\
\hline & & \\
\hline Product diversity & & 74.50 \\
\hline Single line product & 79 & 25.50 \\
\hline Multi products & 27 & 100 \\
\hline Total & 106 & \\
\hline
\end{tabular}

Source: Field survey (2016)

\section{Analysis of data and research questions}

Strategic HRM by SMEs

Is strategic HRM practiced by Palestinian firms?

Table 2

\begin{tabular}{|c|c|c|c|c|c|c|c|}
\hline $\mathrm{S} / \mathrm{n}$ & Variable & SA & A & $\mathrm{U}$ & $\mathrm{D}$ & SD & Remark \\
\hline 7 & \begin{tabular}{|ll}
$\begin{array}{l}\text { Structured } \\
\text { mechanism }\end{array}$ & planning \\
\end{tabular} & \begin{tabular}{|l}
4 \\
$(3.8)$
\end{tabular} & \begin{tabular}{|l}
40 \\
$(40.6)$
\end{tabular} & $\begin{array}{l}4 \\
(5.7)\end{array}$ & $\begin{array}{l}50 \\
(50.0)\end{array}$ & 0 & Disagreement \\
\hline 8 & $\begin{array}{l}\text { Differentiation } \\
\text { strategy }\end{array}$ & $\begin{array}{l}9 \\
(9.4)\end{array}$ & $\begin{array}{l}38 \\
(37.7)\end{array}$ & $\begin{array}{l}4 \\
(5.7)\end{array}$ & $\begin{array}{l}42 \\
(43.4)\end{array}$ & $\begin{array}{l}3 \\
(3.8)\end{array}$ & Disagreement \\
\hline 9 & $\begin{array}{l}\text { Sales growth/low cost } \\
\text { strategy }\end{array}$ & 0 & $\begin{array}{l}46 \\
(45.3)\end{array}$ & $\begin{array}{l}3 \\
(3.8)\end{array}$ & $\begin{array}{l}50 \\
(49.0)\end{array}$ & $\begin{array}{l}2 \\
(1.9)\end{array}$ & Disagreement \\
\hline 10 & $\begin{array}{l}\text { Mixed strategy/ } \\
\text { revenue growth }\end{array}$ & 0 & $\begin{array}{l}37 \\
(34.9)\end{array}$ & $\begin{array}{l}6 \\
(5.7)\end{array}$ & $\begin{array}{l}59 \\
(55.7)\end{array}$ & $\begin{array}{l}4 \\
(3.3)\end{array}$ & Disagreement \\
\hline
\end{tabular}

The research showed that majority of the SMEs in Palestine does not adopt strategic HRM. This is an indication that majority of the respondent's staff of the SMEs was in disagreement that their firms does not have structured planning mechanism, differentiation strategy, low cost strategy/sales growth and mixed strategy. This concludes that the disagreement to these variables implies that these firms do not adopt them in their management processes in return this will affect their performance level.

How does SHRM affect the level of competition in Palestinian firms?

Table 3

\begin{tabular}{|l|l|l|l|l|l|l|l|}
\hline S/n & Variable & SA & A & U & D & SD & Remark \\
\hline 11 & $\begin{array}{l}\text { Do things that gives us } \\
\text { edge over our rivals }\end{array}$ & $\begin{array}{l}20 \\
(23.6)\end{array}$ & $\begin{array}{l}58 \\
(56.6)\end{array}$ & $\begin{array}{l}7 \\
(7.5)\end{array}$ & $\begin{array}{l}11 \\
(12.3)\end{array}$ & 0 & Agreement \\
\hline 12 & $\begin{array}{l}\text { Frequency of customer } \\
\text { complaints }\end{array}$ & 0 & $\begin{array}{l}13 \\
(11.3)\end{array}$ & $\begin{array}{l}33 \\
(28.5)\end{array}$ & $\begin{array}{l}65 \\
(58.5)\end{array}$ & 2 & Disagreement \\
\hline
\end{tabular}


The respondents showed that the adoption of strategic HRM will enhance the ability of SMEs to do things that gives them edge over others and as well enable them to experience growth in customer base. The result from the question item 12 indicated that none of the SMEs is best in terms of attaining to customer complaints; hence none of them could satisfy customers need effectively.

\section{Hypotheses testing}

H0 1: Adoption of strategic HRM has no significant effect on performance of SMEs Hypothesis one was testing with questionnaire item 7 and 8

Table 4

\begin{tabular}{|l|l|l|l|l|l|l|}
\hline Variable & Data 1 & Data 2 & Rank 1 & Rank 2 & D & D $^{2}$ \\
\hline A & 3 & 11 & 2 & 3 & 1 & 1 \\
\hline B & 45 & 39 & 4 & 4 & 0 & 0 \\
\hline C & 5 & 5 & 3 & 2 & 1 & 1 \\
\hline D & 52 & 44 & 5 & 5 & 0 & 0 \\
\hline E & 0 & 4 & 1 & 1 & 0 & 0 \\
\hline
\end{tabular}

Calculating the Spearman Rank correlation coefficient of ranked data, $\mathrm{R}=1-\left(6 \sum \mathrm{d} 2\right) / \mathrm{n}(\mathrm{n} 2-1)$

Analysis of the result, Spearman rank correlation (calculated) $=0.9$ Spearman rank (table) at $\mathrm{p}=$ $0.05=0.900$

Degree of freedom (DF) $=3$

This shows strong positive correlation between strategic HRM and performance level of SMEs in Palestine. On the other hand, adoption of strategic HRM has significant effect on performance level of SMEs in Palestinian firms. Since the p value is below the $5 \%$ level of significance for this study. Therefore, the study rejects the null hypothesis that adoption of strategic HRM does not have any effect on performance level of SMEs in Palestine.

H02: Adoption of strategic HRM does not have significant effect on level of competition of SMEs in Palestine.

Hypothesis two was testing with questionnaire item 11 and 12

Table 5

\begin{tabular}{|l|l|l|l|l|l|l|}
\hline Variable & Data 1 & Data 2 & Rank 1 & Rank 2 & D & \multicolumn{1}{c|}{$\mathbf{D}^{\mathbf{2}}$} \\
\hline A & 25 & 0 & 4 & 1 & 3 & 9 \\
\hline B & 60 & 12 & 5 & 3 & 2 & 4 \\
\hline C & 8 & 30 & 2 & 4 & 2 & 4 \\
\hline D & 13 & 62 & 3 & 5 & 2 & 4 \\
\hline E & 0 & 2 & 1 & 2 & 1 & 1 \\
\hline
\end{tabular}

Using $\mathrm{R}=1-\left(6 \sum \mathrm{d} 2\right) / \mathrm{n}(\mathrm{n} 2-1)$

Analysis of the result, the spearman rank correlation (calculated) $=0.1$ Spearman rank (table) at $\mathrm{p}=0.05=0.198$

Degree of freedom $=3$

These represent strong positive rank correlation between strategic HRM and SMEs competition level. This implies that the adoption of strategic HRM influences competition in small and medium enterprises. The p value is below the $5 \%$ level of significance for this study. Therefore, the study rejects the null hypothesis that adoption of strategic HRM does not have significant effect on level of competition of SMEs in Palestine. 


\section{CONCLUSION}

An effective Human Resources Management gives chance employees to contribute effectively and productively to the overall company direction and the accomplishment of the organization's goals and objectives. In working life, the most important value is employees. That is why Human Resources Management is the key factor for success of a business. Being a global world and being a part of global competitive markets processes force businesses to manage human factor more truly for every level.

A growing number of sources in HRM literature support the change and development of Human Resources perspectives from personnel management to HRM and then to Strategic HRM; they claim that, the human resources are the companies' most important assets, and effective management of these resources will contribute to the sustainable competitive advantage of firms. The survey showed the level of use and effect of strategic HRM on SMEs in Palestine. Descriptive and spearman rank correlation indicated the following findings Strategic HRM is an important and indispensable tool for any organization performance and for any organization that wants to gain competitive advantages over others. The study reveals that a genuine application of strategic HRM by SMEs will enhance staff and organizational performances. Strategic HRM has effect on level of competition of SMEs in Palestine.

\section{References}

1. Appelbaum, E., Bailey, T., Berg, P., \& Kalleberg, A. (2000). Manufacturing Competitive Advantage: The Effects of high performance work systems on plant performance and company outcomes: New York: Cornell UN Press.

2. Armstrong, M.A. (2009). A Handbook of Human Resources Management. (11th Ed.).London: Kogan Page.

3. Armstrong, M. \& Baron, A. (2004). Managing performance: Performance Management in Action. London: CIPD.

4. Bamberger, P., \& Meshoulam, H. (2000).Human Resource Strategy: Formulation, Implementation and Impact.

5. Barney, J. (2001).Is resource-based view a useful perspective for strategic management research? Yes. Academy of Management Review. 26(1), 41-56.

6. Beverly Hills. Barney, J. (1995). Looking Inside for Competitive Advantage. Academy of Management Executive.9 (4), 49-61.

7. Becker, B.E., Huselid, M.A., \& Urich, D. (2001). The Human Resource Scorecard: linking People, Strategy and Performance. Boston: Harvard Business School Press.

8. Boxall, P., \& Purcell, J. (2003). Strategy and Human Resource Management. London: Macmillan.

9. Boxall, P., \& Purcell, J. (2008).Strategy and Human Resources Management. Basingstoke: Palgrave Macmillan.

10. Cooke, F., L., Shen, J., \& McBride, A. (2005). Outsourcing Human Resource as a Competitive Strategy. Human Resource Management Journal. 44(4), 413-432.

11. Delery, J., \& Doty, H. (2000). Modes of theorizing in Strategic Human Resource Management: Tests of universalistic, contingency and configurationally performance predictions. Academy of Management Journal. 39(4), 802-835.

12. Dyer, L. \& Reeves, T. (2003). Human resource strategies and firm performance. The International Journal of Human Resource Management. 6(3), 650-670.

13. Dyer, J. (2005).Human Resource Management: Evolving Roles and Responsibilities. Washington DC: Bureau of National Affairs.

14. Edwards, T., \& Rees, C. (2006). International Human Resource Management: Globalization, National Systems and Multinational Companies. 
15. Harlow: Prentice Hall. Finegold, D., \& Frenkel, S. (2006). Managing people where people really matter. The management of human resource in biotech companies. International Journal of Human Resource Management. 17(1), 1-24. Grant, R. (2008). Contemporary Strategy Analysis. (6th Ed.) Oxford: Blackwell.

16. Guest, D., Michie, J., Sheehan, M., \& Conway, N. (2000). Employment Relations, Human Resource Management and Business Performance. London: CIPD.

17. Guest, D. (2001).Human Resource Management: When research confronts theory. International Journal of Human Resources Management. 12(7), 1092-1106. International Journal of Humanities and Social Science Vol. 2 No. 10 [Special Issue - May 2012] 70

18. Guest, D. Michie, J., Conway, N., \& Sheehan, M. (2003). Human resource management and performance. British Journal of Industrial Relations. 4(2), 291-314.

19. Huang,G.,Roy,M.,Ahmed,Z.,Heng,J.,\& Lim,J.(2002).Benchmarking the Human Capital Strategies of MNCs in Singapore. Benchmarking.9 (4), 357-373.

20. Huselid, M. (2005). The impact of human resource management practices on turnover, productivity and corporate financial performance. Academy of Management Journal 38(3), 635-672.

21. Kelliher, C., \& Perret, G. (2001). Business Strategies and approaches to HRM: A Case Study of new developments in the UK restaurant industry. Personal Review 30(4), 421-437.

22. Lau, C., \& Ngo, H. (2004).The HR System, Organizational Culture and Product Innovation. International Business Review.13, 685-703.

23. Legge, K. (2005). Human Resource Management Rhetoric and Realities. London: Palgrave Macmillan.

24. Leung, A. (2003). Different ties for different recruitment practices of entrepreneurial firms at different development phases. Human Resources Management Journal. 42(4), 303-320.

25. MacDuffie, J. P. (2005). Human Resource bundles And Manufacturing Performance. Industrial Relations Review. 48(2), 199-221.

26. Marchington, M., \& Grugulis, I. (2000). Best Practice Human Resource Management: perfect opportunity or dangerous illusions? International Journal of Human Resource Management. 41(6), 1029-1056.

27. Marchington, M., \& Zagelmeyer, S. (2005). Foreword: Linking HRM and performance -a never ending search? Human Resource Management Journal. 15(4), 3-8.

28. Marchington, M., \& Wilkinson, A. (2008). Human Resource Management at Work: People Management and Development. (4th Ed.). Harlow: Pearson Education. Pfeffer, J. (2001). Fighting the war for Talent is Hazardous for your Organization. Stanford: Pearson Education.

29. Porter, M. (1985). Competitive Advantage: Creating and Sustaining Superior Performance. New York: Free Press.

30. Purcell, J. (2001). The Meaning of Strategy in Human Resource Management: A Critical Text. (2nd Ed.). London: Thompson Learning.

31. Purcell, J., Hutchinson, S., Kinnie, S. (2003).Understanding the Role and Performance Link: Unlocking the Black Box. London: CIPD.

32. Purcell, J., Hutchinson, S. (2007). Frontline managers as agents in the HRM-performance causal chain: theory analysis and evidence. Human Resource Management Journal. 17(1), 3-20.

33. Redman, T., \&Wilkinson, A. (2006). Contemporary Human Resource Management: Texts and Cases. (Eds.) Harlow: Pearson Education. Robinson, R., Pearce. \& Mital, A. (2008).

34. Strategic Management: Formulation, Implementation and Control. New Delhi; McGraw Hill Education.

35. Rutherfold, M., Buller P., \& McMillan, P. (2003). Human resource management over the life cycle of small to medium-sized firms. Human Resource Management Journal.23 (8), 769-780.

36. Scholes, K., \& Johnson, G. (2007). Explaining Corporate Strategy. Hempstead: Prentice Hall. Schuler, R., \& Jackson S. (1987). Linking competitive strategies with human resources management practices. Academy of Management Executive .9(3), 207-219. 